\title{
Stressful Life Events and Women's Mental Health During Pregnancy and Postpartum Period ${ }^{1}$
}

\author{
Patrícia Alvarenga \\ Universidade Federal da Bahia, \\ Salvador-BA, Brazil
}

\author{
Giana Bitencourt Frizzo \\ Universidade Federal do Rio Grande do Sul, \\ Porto Alegre-RS, Brazil
}

\begin{abstract}
Stressful life events can affect the mental health of women during pregnancy and the postpartum period. This study investigated the relationship between sociodemographic variables, stressors during pregnancy and women's mental health during pregnancy and postpartum. Seventy-nine pregnant women responded to the Self Reporting Questionnaire (SRQ-20) and, in the first month of the baby's life, to the Stressful Life Events Inventory and the Beck Depression Inventory (BDI-I). Regression analysis revealed that: (a) the score of common mental disorders in pregnancy was the only significant predictor of postpartum depression; (b) when the effects of postpartum depression on the perception of stressful life events were controlled, the impact of stressful life events on the variance in common mental disorders during pregnancy disappeared, and only the income remained as a significant predictor. These findings indicate the stability of the symptoms of mental disorders from pregnancy to the postpartum period.
\end{abstract}

Keywords: stress, mental health, pregnancy, puerperium, postpartum depression

\section{Eventos de Vida Estressores e a Saúde Mental da Mulher na Gestação e no Puerpério}

\begin{abstract}
Resumo: Eventos estressores podem afetar a saúde mental da mulher durante a gestação e o puerpério. Este estudo investigou relações entre variáveis sociodemográficas, estressores durante a gestação e a saúde mental da mulher na gestação e no puerpério. Setenta e nove gestantes responderam ao Self Reporting Questionnaire (SRQ-20), e no primeiro mês de vida do bebê, responderam ao Inventário de Eventos de Vida Estressores (ISLE) e ao Inventário Beck de Depressão (BDI-I). Análises de regressão revelaram que: (a) o escore de transtornos mentais comuns na gestação foi o único preditor significativo da depressão pós-parto; (b) quando o efeito da depressão pósparto sobre a percepção dos eventos estressores foi controlado, o impacto dos eventos estressores sobre a variância nos transtornos mentais comuns na gestação desapareceu, e apenas a renda permaneceu como preditor significativo. Esses achados indicam a estabilidade dos sintomas de transtornos mentais da gestação para o puerpério.
\end{abstract}

Palavras-chave: stress, saúde mental, gravidez, puerpério, depressão pós-parto

\section{Eventos de Vida Estresantes y Salud Mental de Mujeres Durante el Embarazo y el Postparto}

\begin{abstract}
Resumen: Los eventos estresantes pueden afectar la salud mental de las mujeres durante el embarazo y el puerperio. Este estudio investigó la relación entre variables sociodemográficas, estresores y la salud mental de mujeres durante el embarazo y el postparto. Setenta y nueve mujeres embarazadas contestaron al Self Reporting Questionnaire (SRQ-20) y, en el primer mes de vida del bebé, al Inventario de Eventos Estresores de la Vida y el Inventario Beck de Depresión (BDI-I). Análisis de regresión revelaron que: (a) el escore de trastornos mentales comunes en el embarazo fue el único predictor significativo de la depresión postparto; (b) cuando se controlaron los efectos de la depresión postparto en la percepción de los estresores, el impacto de los estresores en la varianza en los trastornos mentales comunes durante el embarazo desapareció, y sólo el ingreso familiar fue un predictor significativo. Estos hallazgos indican la estabilidad de los síntomas de trastornos mentales del embarazo al postparto.
\end{abstract}

Palabras clave: estrés, salud mental, embarazo, puerperio, depresión post-parto

Stressful life events are events and situations that cause physical or emotional discomfort, fatigue, concern, anxiety, frustration, ambivalence or fear (Kanner, Coyne, Schaefer, \& Lazarus, 1981; Rapoport \& Piccinini, 2011). Pregnancy

\footnotetext{
${ }^{1}$ Support: First Projects Program by Foundation for Scientific Research Support from Bahia (FAPESB) (Grant \# 7874/2006).

${ }^{2}$ Correspondence address:

Universidade Federal da Bahia. Programa de Pós-graduação em Psicologia. Rua Aristides Novis, 197, Federação. CEP 40210-730. Salvador-BA, Brazil.

E-mail: palvarenga66@gmail.com
}

demands different adaptations that can cause stress (Dunkel Schetter \& Tanner, 2012). During the first pregnancy, the stress can arise due to the novelty of the situation. Subsequent pregnancies, in addition to the tasks and demands the other children generate, can result in a moderate or even intense overload for the woman. Besides the physical changes characteristic of the pregnancy period, the anxiety about the delivery and the uncertainties about what will follow contribute a lot to the occurrence of concerns, anxiety and stress symptoms during that period (Field, 2011; Piccinini, Carvalho, Ourique, 
\& Lopes, 2012). In that sense, motherhood can be considered a risk factor for women's mental health during pregnancy as well as in the postpartum period (Field, 2011; Ritter, Hobfoll, Lavin, Cameron, \& Hulsizer, 2000; Rodrigues \& Schiavo, 2011). In addition, other stressful events not specifically related to pregnancy and the infant's birth, when present during that period, can also affect women's mental health.

The main mental health problems of pregnant and postpartum women are linked to anxiety and depression symptoms. One of the ways to evaluate this type of symptoms is through the concept of common mental disorder, assessed by SRQ-20 (Mari \& Williams, 1986). The construct refers to a health status of a population of individuals who do not meet the formal criteria for diagnoses of depression or anxiety, but have prominent symptoms that bring a functional disability comparable to or even worse than chronic conditions (Bernardes Santos, Carvalho, \& Araújo, 2014; Santos et al., 2007). In the study by Alvarenga, Dazzani, Alfaya, Lordelo and Piccinini (2012), the mean score of common mental disorders, assessed by means of the SRQ-20, in a sample of 261 pregnant women from Salvador/BA amount to 8.01 (out of 20 items). This score is high, as it corresponds to the instrument's cut-off point, which distinguishes between women without any sign of mental disorder from women with suspected mental disorder.

According to the international literature, postpartum depression occurs in around 10 to $20 \%$ of postpartum women (Cantilino, Zambaldi, Sougey, \& Rennó Júnior, 2010; Dunkel Schetter \& Tanner, 2012). In an American study, however, $39 \%$ of mothers were considered depressed during the postpartum period, in a non-representative sample in the interior of the United States (McCoy, Beal, Shipman, Payton, \& Watson, 2006). In Brazil, high frequencies were also found, ranging between $20 \%$ and $28 \%$ (Moraes et al., 2006). Anyway, a higher frequency has been found in studies with participants from a low socioeconomic status (30$40 \%$ ), while a prevalence rate of about $20 \%$ was found in population-based studies with probabilistic samples (Lobato, Moraes, \& Reichenheim, 2011). In addition, when higherincome countries were compared with lower-income nations, there seems to be an increase in the prevalence of postpartum depression in the latter (Parsons, Young, Rochat, Kringelbach, \& Stein, 2011; Verkuijl et al., 2014).

For the sake of contextualization, in a Brazilian study, a depression prevalence rate of $16 \%$ was indicated in a lowincome population in the South of the country, including men and women. When analyzed separately, however, the mean prevalence among women corresponded to 21\% (Cunha, Bastos, \& Del Duca, 2012). Although the study did not specify these women's age, several others indicated a high prevalence of these symptoms in the postpartum (Cantilino et al., 2010; Dunkel Schetter \& Tanner, 2012), which can vary a lot according to methodological factors, such as the heterogeneity of the samples (Cantilino et al., 2010; Lobato et al., 2011), some of which are higher than the rates found by Cunha et al. (2012).

The stress experienced during pregnancy is also related to symptoms of mental disorders, and particularly with depression during pregnancy and postpartum (Meijer et al., 2014). Adverse events like abandonment by the child's father or the ambivalence of the infant's father during the pregnancy, great financial difficulties (Dunkel Schetter \& Tanner, 2012; O'Hara, 1997) and not planning the pregnancy (Brito, Alves, Ludermir, \& Araújo, 2015) are some examples of factors that can predispose women to depressive symptoms during the postpartum period.

Depression during pregnancy has been less investigated in the literature when compared to postpartum depression (Davalos, Yadon, \& Tregellas, 2012; Field, 2011). Although the frequency ranges between 6 and 38\% (Field, 2011), studies indicate that, when women experience symptoms of stress, anxiety and depression during pregnancy, these symptoms are later related to postpartum depression (Figueira, Diniz, \& Silva Filho, 2011; Rodrigues \& Schiavo, 2011). Studies also show that there are specific stressful events during that period, related to the body changes and concerns with the infant's future for example (Lobel et al., 2008). On the other hand, there are signs that the absence of stressful events during pregnancy is associated with the decline of depression symptoms between the pre and postpartum periods (Ritter et al., 2000).

In the literature, it is shown that both pregnancy and postpartum, as well as all the significant changes that take place during this period can act as risk factors for women's mental health. The studies also indicate the impact of variables associated with the socioeconomic status on mental health in this stage of life. The objective in this study was to investigate the relations among sociodemographic variables, stressful life events experienced during pregnancy and women's mental health during pregnancy and postpartum. The following hypotheses were tested: (a) the higher the number of stressful events and their perceived impact, the higher the number of symptoms of common mental disorders during pregnancy and the higher the level of postpartum depression; (b) the higher the number of symptoms of common mental disorders during pregnancy, the higher the level of postpartum depression. As stressful life events experienced during pregnancy were assessed soon after the infant's birth, the moderating effect of postpartum depression on the participants' perception of its impact was investigated.

\section{Method}

\section{Participants}

The study used a correlational design. Seventy-nine pregnant women participated in the study, selected through convenience sampling at four public maternity hospitals in the city of Salvador. The participants were in the third trimester of pregnancy during the first phase of data collection, when sociodemographic information was collected. To be included in the sample, pregnant women should be between 19 and 40 years of age and live in the city of Salvador. Pregnant women's age ranged between 19 and 39 years $(M=27.63 ; S D$ $=5.52$ ). Educational level ranged between five and 16 years of education, and the mean age of the sample was 10.81 years 
$(S D=2.16)$. Only $35.4 \%$ of the participants worked outside the home and the family income ranged from 250.00 to $3,000.00$ reais, with a mean income of $821.68(S D=516.50)$.

Slightly more than half of pregnant women were primiparous $(51 \%)$, and other participants had between one and four children $(M=0.76 ; S D=0.95)$. Less than half of the women in the sample (40\%) indicated that they had planned pregnancy. As regards health conditions during pregnancy, $21.5 \%$ of participants reported complications (such as hypertension, threat of abortion, thrombosis, among others), and $13.9 \%$ affirmed having chronic health problems, such as hyper or hypotension, hypothyroidism, diabetes and asthma. All infants were born full-term, had no physical malformations or diagnosis of chronic health problems.

\section{Instruments}

Inventory of Stressful Life Events - ISLE. This instrument is an adaptation of the Inventário de Eventos de Vida Estressores na Adolescência [Stressful Life Events in Adolescence Inventory] (IEEA; Kristensen, Leon, D'Incao, \& Dell'Aglio, 2004). It consists of 64 items of stressful life events, and was originally constructed in Portuguese. For the purpose of this study, the total number of items was maintained, but with some adaptations to adapt to the age range of the participants and also consider pregnancy-related events, which play an important role in woman's mental health in this stage of life (DiPietro, Novak, Costigan, Atella, \& Reusing, 2006). It is important to highlight that participants were instructed to answer concerning the presence/absence and the impact of the 64 events, considering only the pregnancy period. The items that specifically referred to stressors related to pregnancy were as follows: 8 - Experiencing problems and doubts regarding changes in body and appearance; 15 -Conflicts with family due to pregnancy; 41 - Receiving the news about the pregnancy; 42 - Trying to have an abortion; 56 - Partner's non acceptance of the pregnancy; 62 - Suffering nausea during pregnancy; 63 - Pregnancy being unexpected; and 64 - Not having good medical care during pregnancy. For each item, the participant should indicate whether the event had occurred or not in the course of the nine months of pregnancy, and then point the impact attributed to each event on a fivepoint Likert scale $(1=l o w, 5=h i g h)$. The frequency and impact of events were considered separately for the analyses. In the study by Kristensen et al. (2004), internal consistency for frequency was .90, and for impact .93. The version used in this study revealed an internal consistency of .92 in frequency analysis and .93 in impact analysis.

Self-Report Questionnaire of Minor Psychiatric Disorders - SRQ-20. This instrument was developed by Harding et al. (as cited by Mari \& Williams, 1985). The SRQ-20 is the 20-item version of the SRQ-30 to screen for non-psychotic mental disorders, particularly depression and anxiety symptoms. The answers are in the yes/no form. Each affirmative answer is scored 1 . The final score is reached by adding up these scores. The scores obtained are related to the probability that a non-psychotic disorder is present, ranging from 0 (no probability) to 20 (extreme probability). The cut-off point of eight points, that is, eight "yes" answers or more, was used to classify each mother as "participant with suspected mental disorder" or as "participant without suspected mental disorder (Mari \& Williams, 1986). The Brazilian version of the SRQ-20 was used, validated by Mari and Williams (1986) and reassessed by (Gonçalves, Stein, \& Kapczinski, 2008). The internal consistency ratio of the Brazilian version was .86 (Gonçalves et al., 2008). Some studies have shown that this instrument has been indicated as an alternative to screen for cases of postpartum depression until three months after the infant's birth, with accuracy similar to that of the Edinburgh Postpartum Depression Scale - EPDS (Santos et al., 2007).

Beck Depression Inventory I - BDI-I (Beck \& Steer, 1993). This instrument is a self-reported symptom scale that consists of 21 items with different alternative answers on how the individual has felt recently, and which correspond to different levels of depression severity. The total score of the individual items is a dimensional score of the depression intensity and can be classified in the following levels: mild (from 12 to 19 points), moderate (from 20 to 35 points) or severe (more than 36 points). The total score can vary from zero to 63 points. For this study, the Portuguese version of the Inventory validated by Cunha (2001) was used, whose internal consistency (Cronbach's alpha) corresponded to .84, with a test-retest correlation coefficient of .95 .

\section{Procedure}

Data collection. Data were collected in two phases. In the third trimester of the pregnancy, pregnant women were invited to participate in a longitudinal study, which would monitor families between pregnancy until the eighth month of the infant's life. The recruiting and the first phase of data collection took place between August 2007 and May 2008. After completing the Free and Informed Consent Form, in which they agreed to participate in the research, they individually answered, at the hospital where they received prenatal care, a Form on Sociodemographic Data and Health of the Pregnant Woman and the SRQ-20 for mental health assessment. In the second phase of data collection, during the infant's first month of life, the participants received a home visit, during which they answered the Inventory of Stressful Life Events (IEE), reporting on the stressful life events they had experienced in the course of the pregnancy period, and the Beck Depression Inventory (BDI-I). Psychology students collected the data at maternity hospitals and homes after a 20 hour training period.

Data analysis. The data were analyzed using the software SPSS 18.0. Initially, central trend (mean and standard deviation) measures and absolute and relative frequencies were explored for the following variables: frequency and impact of stressful events, frequency of common mental disorder symptoms and depression score. Sociodemographic variables and total scores of all instruments used were inserted in correlation analyses (Pearson). Hierarchical regression analyses were applied to examine the predictive power of the stressful life events and of sociodemographic variables on mental health during pregnancy and postpartum. The variable postpartum depression 
was inserted as a moderating variable in the regression model, which included the score of common mental disorders during pregnancy as a criterion variable to control for the effect of depression on the perceived stressful events. The theoretical study model was tested in hierarchical regression analyses. In the two regression models tested, the total impact score of the stressful events as perceived by the participant was included as a predictor variable, instead of the total frequency of events experienced. This choice is justified by the wide range of life events included in the scale used, turning the perceived impact into a more suitable measure to compare the scores among the participants. To give an example, some participants reported a high frequency of low-impact events, while others informed a low frequency, but related to events with a high potential for stress. These nuances are measured more precisely by the impact level of the events than their frequency, which would tend to equal the profiles of the pregnant women exposed to highly distinct types of stressors. The predictors were introduced in the same order as they appear in the regression tables. Significance was set at.05.

\section{Ethical Considerations}

The study complies with all ethical standards for research involving human beings and was approved on September $27^{\text {th }}$ 2007 by the Ethics Committee at the School of Philosophy and Human Sciences of Universidade Federal da Bahia (UFBA), in compliance with the guidelines and standards of National Health Council Resolution 196/96 - Ministry of Health. Mothers with scores that indicated suspicion of mental disorder on the SRQ-20 or moderate or severe depression on the BDI, as well as mothers who voluntarily manifested their interest in or need for psychological care were forwarded to the Psychology Service at UFBA.

\section{Results}

The mean frequency of stressful life events the participants experienced during their pregnancy was 13.63 events $(S D=9.63)$, and the five most frequent events were experiencing nausea during the pregnancy (81\%), having debts $(75 \%)$, having problems and doubts on the bodily and appearance changes (67\%), not having money (62\%) and having a nervous breakdown (62\%). As for the perceived impact, the mean total sum of the impact of events experienced was $48.30(S D=4.58)$, and the seven events considered the most striking according to the participants were suffering punishments $(M=4.83 ; S D=0.4 ; F=8 \%)$, death of one of the parents $(M=4.5 ; S D=0.83 ; F=8 \%)$, being prevented from seeing one's parents $(M=4.5 ; S D=1.22 ; F=8 \%)$, being expelled from one's home $(M=4.5 ; S D=0.75 ; F=10 \%)$, being raped $(M=4.5 ; S D=1 ; F=5 \%)$, suffering an accident $(M=4.5 ; S D=0.7 ; F=2 \%)$, and suffering physical aggression by the partner $(M=4.5 ; S D=0.83 ; F=8 \%)$. The frequency of the events perceived to be the most striking reveals that few participants experienced them, that is, that the most striking events were hardly frequent in the sample.

The assessment of participants' mental health during the third trimester of the pregnancy revealed a mean 8.57 symptoms of common mental disorders $(S D=3.40)$. Signs of common mental disorders were present in $63 \%$ of the women, who were classified with suspicion of mental disorder. During the infant's first month of life, the participants' mean depression score was $13.87(S D=8.84)$. Concerning the severity of the depressive symptoms, 30.4\% had signs of mild depression, $16.5 \%$ moderate depression and $3.8 \%$ severe depression.

In Table 1, Pearson correlation coefficients are displayed among the scores of stressful life events (ISLE), common mental disorders (SRQ-20), postpartum depression (BDI) and sociodemographic variables. All correlations, although significant, were weak. The total number of stressful events experienced during the pregnancy was correlated with the total score on the SRQ-20 $(r=.33 ; p<.01)$ and the BDI $(r=$ $.19 ; p<.05)$, and the total sum of the impact of the stressful events was also correlated with these two variables $(r=.32 ; p$ $<.01$ and $r=.23 ; p<.05$, respectively). In addition, the score on the SRQ-20 was correlated with the BDI score $(r=.34 ; p$ $<.01)$. Finally, family income was negatively correlated with the score on the SRQ-20 $(r=-.23 ; p<.05)$, and maternal educational level was negatively correlated with the BDI score $(r=-.23 ; p<.05)$.

In the first regression, the variable common mental disorders (SRQ-20) was inserted as the criterion variable.

Table 1

Correlations (Pearson) Among Stressful Life Events (SEI), Minor Psychiatric Disorders (SRQ-20), Postpartum Depression (BDI) and Sociodemographic Variables $(N=79)$

\begin{tabular}{|c|c|c|c|c|c|c|c|c|}
\hline & 1 & 2 & 3 & 4 & 5 & 6 & 7 & 8 \\
\hline 1. SEI events & - & & & & & & & \\
\hline 2. SEI impact & $.96 * *$ & - & & & & & & \\
\hline 3. SRQ-20 & $.33 * *$ & $.32 * *$ & - & & & & & \\
\hline 4. BDI & $.19^{*}$ & $.23 *$ & $.34 * *$ & - & & & & \\
\hline 5. Age & -.09 & -.06 & -.07 & -.09 & - & & & \\
\hline 6. Educational level & -.13 & -.14 & -.16 & $-.23 *$ & .11 & - & & \\
\hline 7. Children & .12 & .15 & .07 & .05 & $.22 *$ & $-.30 * *$ & - & \\
\hline 8. Income & -.06 & -.02 & $-.23 *$ & -.09 & .14 & $.30 * *$ & -.04 & - \\
\hline
\end{tabular}

${ }^{*} p<.05 . * * p<.01$. 
Due to the correlation verified between the family income and the common mental disorders during pregnancy, this sociodemographic variable was also included as a predictor in the regression model, together with the impact of the stressful events (ISLE).

The moderate positive correlation between the product of the impact of the stressful events (ISLE) and postpartum depression (BDI score) and the common mental disorders (SRQ-20), corresponding to $0.46(p=.01)$, indicated the moderating effect of the variable postpartum depression, which was inserted as a moderating variable in the equation (ISLE X BDI). Table 2 displays the summary of this regression analysis. The beta coefficients, $t$ coefficients and significance levels are informed for each of the levels tested, as well as the variance analysis coefficients and adjusted $R^{2}$.

As shown in Table 2, the third and final regression level, with all the variables included, indicates that, even after inserting all variables in the model, for each additional unit in the family income, the common mental disorder score dropped by 0.001 . Nevertheless, the impact of the stressful life events included in the analysis, after the inclusion of postpartum depression as a moderating variable (ISLE X BDI), which was significant before the insertion of the moderating variable, lost its explanatory power $(p=.62)$. The multiple regression model, considering all predicting variables, explained $22 \%$ of the variance in the common mental disorders score of the pregnant women $(F=8.29 ; p=.0001)$. The insertion of postpartum depression into the equation increased the explained variance from $13 \%$ to $22 \%$, which confirms its moderating effect on the relation between the stressful events and the common mental disorders in pregnancy.

Table 2

Summary of Hierarchic Regression Analysis of Minor Psychiatric Disorders Over Family Income and Impact of Stressful Life Events, Moderated by Postpartum Depression $(N=79)$

\begin{tabular}{|c|c|c|c|c|c|}
\hline Levels & $B$ & & $t$ & & $p$ \\
\hline \multirow[t]{2}{*}{ Income } & -0.002 & & -2.04 & & .04 \\
\hline & & $F=4.17$ & $p=.04$ & $R^{2}=.04$ & \\
\hline Income & -0.001 & & -2.06 & & .04 \\
\hline \multirow[t]{2}{*}{ Impact of Stressful Events } & 0.02 & & 2.95 & & .004 \\
\hline & & $F=6.68$ & $p=.002$ & $R^{2}=.13$ & \\
\hline Income & -0.001 & & -2.13 & & .03 \\
\hline Impact of Stressful Events & 0.005 & & 0.49 & & .62 \\
\hline \multirow[t]{2}{*}{ Mod Postpartum Depression (SEI X BDI) } & 0.001 & & 3.14 & & .002 \\
\hline & & $F=8.29$ & $p=.0001$ & $R^{2}=.22$ & \\
\hline
\end{tabular}

The second regression included the variable postpartum depression (BDI) as a criterion variable. Due to the correlation verified between the pregnant woman's education and postpartum depression, this sociodemographic variable was also included as a predictor in the regression model, together with the impact of the stressful life events (ISLE) and the common mental disorders during pregnancy (SRQ-20). Table 3 presents the summary of this regression analysis. The beta coefficients, $t$ coefficients and significance levels are informed for each of the levels tested, as well as the variance analysis coefficients and adjusted $R$.

The results of this regression reveal that the pregnant woman's educational level alone, when inserted as the only predictor in the model, explained $4 \%$ of the variance in postpartum depression, but lost its predictive value after the introduction of the stressful life events and the common mental disorders $(p=.11)$. The impact of the stressful life events did not explain the variance in the postpartum depression at the second and third regression level either, where it was inserted as a predictor ( $p=.06$ and $p=.29$, respectively). Nevertheless, the introduction of the common mental disorders in the equation increased the explained variance from $7 \%$ to $13 \%(F$ $=4.90 ; p=.004)$, revealing that, for each additional symptom in the SRQ-20 (common mental disorders), the puerperal woman's BDI score increased by .72 .
Table 3

Summary of Hierarchic Regression Analysis of Postpartum Depression Over Educational Level of Mother, Impact of Stressful Life Events and Minor Psychiatric Disorders $(N=79)$

\begin{tabular}{llcc}
\hline Levels & $B$ & $t$ & $p$ \\
\hline Educational level & -0.95 & -2.11 & .03 \\
& $F=4.46$ & $p=.03$ & $R^{2}=.04$ \\
Educational level & -0.83 & -1.85 & .06 \\
Impact of Stressful Events & 0.04 & 1.85 & .06 \\
& $F=4.02$ & $p=.02$ & $R^{2}=.07$ \\
Educational level & -0.70 & -1.59 & .11 \\
Impact of Stressful Events & 0.02 & 1.06 & .29 \\
$\begin{array}{l}\text { Minor Psychiatric } \\
\text { Disorders }\end{array}$ & 0.72 & 2.47 & .01 \\
& $F=4.90$ & $p=.004$ & $R^{2}=.13$ \\
\hline
\end{tabular}




\section{Discussion}

This study investigated the relations between stressful life events experienced during pregnancy and woman's mental health during pregnancy and postpartum. The first hypothesis tested established that, the larger the number of stressful events and their perceived impact, the larger the number of symptoms of common mental disorders in pregnancy would be and the higher the level of postpartum depression. This hypothesis was partially confirmed. Although both the number and the impact of stressful events were also correlated with common mental disorders in pregnancy, the regression analysis revealed that, when the moderating effect of postpartum depression on the perceived impact of stressful life events was considered, the explanatory power of the latter disappeared. Similarly, stressful life events no longer predicted postpartum depression after the insertion of common mental disorders in pregnancy in the regression model tested. These findings confirm the second hypothesis tested that, the larger the number of symptoms of common mental disorders in pregnancy, the higher the level of postpartum depression would be.

On the whole, these results indicate that the presence of symptoms of common mental disorders (depression and anxiety) in pregnancy was the most robust predictor of postpartum depression. Hence, the hypothesis should be taken into account that, although anxiety and depression indicate the woman's emotional response to specific and transitory circumstances of pregnancy and the postpartum period, these symptoms can also indicate characteristic of more persistent and stable psychological functioning in different life periods (DiPietro et al., 2006; McCoy et al., 2006). Thus, although pregnancy and postpartum can constitute risk factors for woman's mental health, this risk is particularly high for women with some background history of mental health problems. In view of the inconsistency in the findings of studies intended to identify risk factors for postpartum depression in the literature, some authors (Conde \& Figueiredo, 2003; O'Hara, 1997) have proposed the woman's psychological adjustment before and during the pregnancy as one of the most important risk factors.

Some recent studies seem to point in the same direction, especially from the pregnancy to the postpartum period (Field et al., 2010; Figueiredo, Pacheco, \& Costa, 2007; Moss, Skouteris, Wertheim, Paxton, \& Milgrom, 2009). In that sense, this study confirms the impact of stressful events in pre and postpartum period on the woman's mental health, in line with the literature in the area (Lobel et al., 2008; O'Hara, 1997; Rodrigues \& Schiavo, 2011). Nevertheless, the findings highlight the fact that this impact can change according to other variables, such as more stable characteristics of women's psychological functioning for example (DiPietro et al., 2006). In addition, anxiety and pre and postnatal depression have been related with several losses in child development, in the outcomes: premature birth and low birth weight (Barrios, Sanchez, Qiu, Gelaye, \& Williams, 2014; DiPietro et al., 2006; Dunkel Schetter \& Tanner, 2012) as well as in difficulties in the mother-infant interaction (Field, 2011; Frizzo \& Piccinini, 2005), which underlines the relevance of these findings.
The family income was also positively correlated with the common mental disorders in pregnancy and, when inserted in the regression model, even after the introduction of all variables in the equation, maintained its explanatory power, serving as a relevant predictor of the common mental disorders in the prenatal period. Some studies confirmed the predictive value of income for mental disorders in this period (Alvarenga et al., 2012; O'Hara, 1997). Anyway, this relation found in the study may be due to the fact that the sample involved a highly vulnerable population from the economic viewpoint, including participants with a very low income. These characteristics of the sample could explain the relation found as, in the general population, the prevalence of mental disorders has been associated with socioeconomic indicators (Cunha et al., 2012; Economou, Madianos, Peppou, Patelakis, \& Stefanis, 2013).

Similarly, the mother's educational level was negatively correlated with postpartum depression, although this relation was not confirmed in the regression analysis. Therefore, future studies should better investigate these relations. Anyway, there is countless evidence in literature indicating that, among women with lower educational level, the risk of postpartum depression and symptoms of common mental disorders in postpartum period is higher (Alvarenga et al., 2012; Economou et al., 2013; Morais, Fonseca, David, Viegas, \& Otta, 2015). Cunha et al. (2012) argue that conditions like low income and low education are commonly associated with other adverse events, such as unemployment, and that these exclusive or combined conditions can help to explain the presence of a state of despair which, in turn, would reduce the individuals' capacity to cope with stressful situations. It is also possible that the lesser access to education makes it difficult to develop effective behavioral resources to cope with new and complex situations like motherhood, for example, which could also be related to the emergence of depression and other symptoms of mental disorders in this context.

This study presents some limitations. In first place, participants only reported stressful events of pregnancy only in the first month of the infant's life, and not in the course of the pregnancy period. This methodological aspect submitted the perception of stressful events to the effects of postpartum depression, which a considerable number of mothers experienced. This effect was partially controlled in the regression analyses, but the study design would gain from a procedure that would guarantee the assessment of these events before the infant's birth. In addition, SRQ-20 is sensitive to recent changes in the individuals' psychological condition, which does not permit the distinction between this type of symptom and an established psychiatric diagnosis. This characteristic can lead to the inclusion of false positives, which are individuals with transitory symptoms. This would entail the increased prevalence of common mental disorders in the sample (Lopes, Faerstein, \& Chor, 2003). Therefore, new studies could develop a more detailed assessment of the mother, in order to truly identify clinical cases of depression and anxiety (Dunkel Schetter \& Tanner, 2012; Lobato et al., 2011).

In sum, this study consistently points towards the stability of mental disorder symptoms between pregnancy and postpartum 
period, as well as to the impact of maternal mental health in both periods on the perception of stressful events. In this sense, the perception and experience of stress during pregnancy seem to depend on more general and stable conditions of psychological functioning of women in a very significant way.

Hence, based on the study findings and on the literature review, it is highly recommendable to assess women's mental health during pregnancy, if possible since the beginning, especially aiming to identify risk situations for postpartum depression. In addition, the assessment of stressful life events can also be a promising strategy, as the experience of stress in pregnant and postpartum women with mental health problems can be more intense, causing great suffering, and having more severe implications for the attachment to be established between mother and child since pregnancy. These strategies can favor the prevention of more severe clinical conditions related to pre and postpartum depression, as well as child development problems.

\section{References}

Alvarenga, P., Dazzani, M. V. M., Alfaya, C. A. S., Lordelo, E. R., \& Piccinini, C. A. (2012). Relações entre a saúde mental da gestante e o apego materno-fetal [Relations between pregnant women's mental health and maternalfetal attachment]. Estudos de Psicologia (Natal), 17(3), 477-484. doi:10.1590/S1413-294X2012000300017

Barrios, Y. V., Sanchez, S. E., Qiu, C., Gelaye, B., \& Williams, M. A. (2014). Risk of spontaneous preterm birth in relation to maternal experience of serious life events during pregnancy. International Journal of Women's Health, 6, 249-257. doi:10.2147/IJWH.S54269

Beck, A. T., \& Steer, R. A. (1993). Manual for Beck Depression Inventory. San Antonio, TX: Psychological Corporation.

Bernardes Santos, K. O., Carvalho, F., \& Araújo, T. M. (2014). Screening of common mental disorders among occupational groups: A review of dimensional structure of self reporting questionnaire-SRQ-20. Occupational and Environmental Medicine, 71(Suppl. 1), A87. doi:10.1136/oemed-2014-102362.271

Brito, C. N. O., Alves, S. V., Ludermir, A. B., \& Araújo, T. V. B. (2015). Postpartum depression among women with unintended pregnancy. Revista de Saúde Pública, 49, 33. doi:10.1590/S0034-8910.2015049005257

Cantilino, A., Zambaldi, C. F., Sougey, E. B., \& Rennó Júnior, J. (2010). Transtornos psiquiátricos no pósparto [Postpartum psychiatric disorders]. Revista de Psiquiatria Clínica, 37(6), 288-294. doi:10.1590/S010160832010000600006

Conde, A., \& Figueiredo, B. (2003). Ansiedade na gravidez: Factores de risco e implicações para saúde e bem-estar da mãe [Anxiety in pregnancy: Risk factors and implications for maternal health and well-being]. Psiquiatria Clínica, 24(3), 197-209.
Cunha, J. A. (2001). Escalas Beck-Manual [Beck Scales - Manual]. São Paulo, SP: Casa do Psicólogo.

Cunha, R. V., Bastos, G. A. N., \& Del Duca, G. F. (2012). Prevalência de depressão e fatores associados em comunidade de baixa renda de Porto Alegre, Rio Grande do Sul. Revista Brasileira de Epidemiologia, 15(2), 346354. doi:10.1590/S1415-790X2012000200012

Davalos, D. B., Yadon, C. A. A., \& Tregellas, H. C. (2012). Untreated prenatal maternal depression and the potential risks to offspring: A review. Archives of Women's Mental Health, 15(1), 1-14. doi:10.1007/s00737-011-0251-1

Dunkel Schetter, C. D., \& Tanner, L. (2012). Anxiety, depression and stress in pregnancy: Implications for mothers, children, research, and practice. Current Opinion in Psychiatry, 25(2), 141-148. doi:10.1097/ YCO.0b013e3283503680

DiPietro, J. A., Novak, M. F. S. X., Costigan, K. A., Atella, L. D., \& Reusing, S. P. (2006). Maternal psychological distress during pregnancy in relation to child development at age two. Child Development, 77(3), 573587. doi:10.1111/j.1467-8624.2006.00891.x

Economou, M., Madianos, M., Peppou, L. E., Patelakis, A., \& Stefanis, C. N. (2013). Major depression in the era of economic crisis: A replication of a cross-sectional study across Greece. Journal of Affective Disorders, 145(3), 308-314. doi:10.1016/j.jad.2012.08.008

Field, T. (2011). Prenatal depression effects on early development: A review. Infant Behavior \& Development, 34(1), 1-14. doi:10.1016/j.infbeh.2010.09.008

Field, T., Diego, M., Hernandez-Reif, M., Figueiredo, B., Deeds, O., Ascencio, A., ... Kuhn, C. (2010). Comorbid depression and anxiety effects on pregnancy and neonatal outcome. Infant Behavior \& Development, 33(1), 23-29. doi:10.1016/j.infbeh.2009.10.004

Figueira, P. G., Diniz, L. M., \& Silva Filho, H. C. (2011). Características demográficas e psicossociais associadas à depressão pós-parto em uma amostra de Belo Horizonte [Demographic and psychosocial characteristics associated with postpartum depression in a sample from Belo Horizonte]. Revista de Psiquiatria do Rio Grande do Sul, 33(2), 71-75. doi:10.1590/S010181082011005000009

Figueiredo, B., Pacheco, A., \& Costa, P. (2007). Depression during pregnancy and the postpartum period in adolescent and adult Portuguese mothers. Archives of Women's Mental Health, 10(3), 103-109. doi:10.1007/ s00737-007-0178-8

Frizzo, G. B., \& Piccinini, C. A. (2005). Interação mãe-bebê em contexto de depressão materna: Aspectos teóricos e empíricos [Mother-baby interaction in the context of maternal depression: Theoretical and empirical issues]. Psicologia em Estudo, 10(1), 47-55. doi:10.1590/S141373722005000100007 
Gonçalves, D. M., Stein, A. T., \& Kapczinski, F. (2008). Avaliação de desempenho do Self-Reporting Questionnaire como instrumento de rastreamento psiquiátrico: Um estudo comparativo com o Structured Clinical Interview for DSM-IV-TR [Performance of the Self-Reporting Questionnaire as a psychiatric screening questionnaire: A comparative study with Structured Clinical Interview for DSM-IV-TR]. Cadernos de Saúde Pública, 24(2), 380-390. doi:10.1590/S0102311X2008000200017

Kanner, A. D., Coyne, J. C., Schaefer, C., \& Lazarus, R. S. (1981). Comparison of two modes of stress measurement: Daily hassles and uplifts versus major life events. Journal of Behavioral Medicine, 4(1), 1-39. doi:10.1007/BF00844845

Kristensen, C. H., Leon, J. S., D’Incao, D. B., \& Dell'Aglio, D. D. (2004). Análise da frequência e do impacto de eventos estressores em uma amostra de adolescentes [Analysis of the frequency and impact of stressful life events in a sample of adolescents]. Interação em Psicologia, 8(1), 45-55.

Lobato, G., Moraes, C. L., \& Reichenheim, M. E. (2011). Magnitude da depressão pós-parto no Brasil: Uma revisão sistemática [The extent of post-partum depression in Brazil: A systematic review]. Revista Brasileira de Saúde Materno Infantil, 11(4), 369-379. doi:10.1590/ S1519-38292011000400003

Lobel, M., Cannella, D. L., Graham, J. E., DeVincent, C., Schneider, J., \& Meyer, B. A. (2008). Pregnancy-specific stress, prenatal health behaviors, and birth outcomes. Health Psychology, 27(5), 604-615. doi:10.1037/ a0013242

Lopes, C. S., Faerstein, E., \& Chor, D. (2003). Eventos de vida produtores de estresse e transtornos mentais comuns: Resultados do Estudo Pró-Saúde [Stressful life events and common mental disorders: Results of the ProSaude Study]. Cadernos de Saúde Pública, 19(6), 17131720. doi:10.1590/S0102-311X2003000600015

Mari, J. J., \& Williams, P. (1985). A comparison of the validity of two psychiatric screening questionnaires (GHQ12 and SRQ-20) in Brazil, using Relative Operating Characteristic (ROC) analysis. Psychological Medicine, 15(3), 651-659. doi:10.1017/S0033291700031500

Mari, J. J., \& Williams, P. (1986). A validity study of a psychiatric screening questionnaire (SRQ-20) in primary care in the city of São Paulo. British Journal of Psychiatry, 148(1), 23-26. doi:10.1192/bjp.148.1.23

Meijer, J. L., Bockting, C. L. H., Stolk, R. P., Kotov, R., Ormel, J., \& Burger, H. (2014). Associations of life events during pregnancy with longitudinal change in symptoms of antenatal anxiety and depression. Midwifery, 30(5), 526-531. doi:10.1016/j.midw.2013.06.008
McCoy, S. J. B., Beal, J. M., Shipman, S. B. M., Payton, M. E., \& Watson, G. H. (2006). Risk factors for postpartum depression: A retrospective investigation at 4-weeks postnatal and a review of the literature. Journal of the American Osteopathic Association, 106(4), 193-198.

Moraes, I. G. S., Pinheiro, R. T., Silva, R. A., Horta, B. L., Sousa, P. L. R., \& Faria, A. D. (2006). Prevalência da depressão pós-parto e fatores associados [Prevalence of postpartum depression and associated factors]. Revista de Saúde Pública, 40(1), 65-70. doi:10.1590/S003489102006000100011

Morais, M L. S., Fonseca, L. A. M., David, V. F., Viegas, L. M., \& Otta, E. (2015). Fatores psicossociais e sociodemográficos associados à depressão pós-parto: Um estudo em hospitais público e privado da cidade de São Paulo, Brasil. Estudos de Psicologia (Natal), 20(1), 40-49. doi:10.5935/1678-4669.20150006

Moss, K. M., Skouteris, H., Wertheim, E. H., Paxton, S. J., \& Milgrom, J. (2009). Depressive and anxiety symptoms through late pregnancy and the first year post birth: An examination of prospective relationships. Archives of Women's Mental Health, 12(5), 345-349. doi:10.1007/ s00737-009-0086-1

O'Hara, M. W. (1997). The nature of postpartum depressive disorders. In L. Murray \& P. J. Cooper (Eds.), Postpartum depression and child development (pp. 3-31). New York, NY: Guilford.

Parsons, C. E., Young, K. S., Rochat, T. J., Kringelbach, M. L., \& Stein, A. (2011). Postnatal depression and its effects on child development: A review of evidence from low- and middle-income countries. British Medical Bulletin, 101(1), 57-79. doi:10.1093/bmb/ldr047

Piccinini, C. A., Carvalho, F. T., Ourique, L. R., \& Lopes, R. S. (2012). Percepções e sentimentos de gestantes sobre o pré-natal [Perceptions and feelings of pregnant women concerning prenatal care]. Psicologia: Teoria e Pesquisa, 28(1), 27-33. doi:10.1590/S0102-37722012000100004

Rapoport, A., \& Piccinini, C. A. (2011). Maternidade e situações estressantes no primeiro ano de vida do bebê [Motherhood and stressful situations in the first year of the baby's life] Psico-USF, 16(2), 215-225. doi:10.1590/ S1413-82712011000200010

Ritter, C., Hobfoll, S. E., Lavin, J., Cameron, R. P., \& Hulsizer, M. R. (2000). Stress, psychosocial resources, and depressive symptomatology during pregnancy in low-income, inner-city women. Health Psychology, 19(6), 576-585. doi:10.1037/0278-6133.19.6.576

Rodrigues, O. M. P. R., \& Schiavo, R. A. (2011). Stress na gestação e no puerpério: Uma correlação com a depressão pós-parto [Stress in pregnancy and puerperium: A correlation with postpartum depression]. Revista Brasileira de Ginecologia e Obstetricia, 33(9), 252-257. doi:10.1590/S0100-72032011000900006 
Santos, I. S., Matijasevich, A., Tavares, B. F., Lima, A. C. C., Riegel, R. E., \& Lopes, B. C. (2007). Comparing validity of Edinburgh scale and SRQ20 in screening for postpartum depression. Clinical Practice and Epidemiology in Mental Health, 3, 18. doi:10.1186/1745-0179-3-18

Verkuijl, N. E., Richter, L., Norris, S. A., Stein, A., Avan, B., \& Ramchandani, P. G. (2014). Postnatal depressive symptoms and child psychological development at 10 years: A prospective study of longitudinal data from the South African birth to twenty cohort. Lancet Psychiatry, 1(6), 454-460. doi:10.1016/S2215-0366(14)70361-X

Patricia Alvarenga is a Professor at Universidade Federal da Bahia.

Giana Bitencourt Frizzo is a Professor at Universidade Federal do Rio Grande do Sul.

Received: June 30, 2015

1st Revision: Mar. 24, 2016

Approved: Apr. 11, 2016

How to cite this article:

Alvarenga, P., \& Frizzo, G. B. (2017). Stressful life events and women's mental health during pregnancy and postpartum period. Paidéia (Ribeirão Preto), 27(66), 51-59. doi: 10.1590/1982-43272766201707 